\title{
ACCIÓN DIRECTA: UNA PLAZA DE NADIE Y DE TODOS
}

\author{
Eduardo Álvarez Pedrosian ${ }^{1}$ \\ Denise Vigo $^{2}$
}

\section{Introducción}

En el contexto de una investigación mayor, con diversos espacios de intervención y prácticas etnográficas más en general, nos encontramos con narrativas urbanas de gran heterogeneidad y riqueza. ${ }^{3}$ Los territorios urbanos del histórico segundo ensanche de Montevideo, conocido técnicamente en su momento como La Ciudad Novísima (1878) (Carmona y Gómez, 2002), constituyen un laboratorio antropológico para la exploración de los fenómenos asociados al habitar y los procesos de subjetivación involucrados en ellos. Se trata de una zona intermedia tanto social como espacial, donde se gestó la moderna clase media que caracterizó al Uruguay del siglo $\mathrm{XX}$, tanto en los imaginarios instituyentes como a partir de diversas materializaciones encarnadas en formas de socialización específicas, sus espacialidades y temporalidades. Olvidado como entidad con características propias, quedó diluido entre los flujos de las redes territoriales más intensas y extensas, en el solapamiento de procesos históricos cargados de implicancias políticas de una verdadera "arena cultural" con sus "ensayos de modernidad y modernización" (Arêas Peixoto y Gorelik, 2016: 16). Lo cierto es que consideramos medular su estudio y análisis, en tanto oportunidad para la colaboración en procesos de transformación y innovación urbana desde la producción de narrativas y sus "saberes habitantes" (Álvarez Pedrosian, 2018b).

\footnotetext{
${ }^{1}$ Universidad de la República, Uruguay. Email: eduardo.alvarez@fic.edu.uy ORCID id: https://orcid.org/0000-0003-1795-7792

${ }^{2}$ Universidad de la República, Uruguay. Email: denisevigo35@gmail.com ORCID id: https://orcid.org/0000-0001-5613-687X

${ }^{3}$ Proyecto I+D Habitares de un Montevideo aún "novísimo": narrativas, procesos de subjetivación y prácticas espaciales en territorios urbanos entre el deterioro y la gentrificación (aprobado académicamente por la Comisión Sectorial de Investigación Científica, CSIC-Udelar); Proyecto Innovaciones Educativas Aprendizajes colaborativos en base a problemáticas convergentes: formación en estudios culturales urbanos (financiado por la Comisión Sectorial de Enseñanza, CSE-Udelar). Ambos proyectos se encuentran enmarcados en el Programa en Comunicación, Arquitectura, Ciudad y Territorio (ACT-Com.) del Laboratorio Transdisciplinario de Etnografía Experimental (Labtee), radicado en la FIC-Udelar.
} 
Dentro de una multiplicidad de territorios y territorialidades en su seno, y siempre atravesadas por redes en escalas de fenómenos variables, la zona presenta realidades que pueden caracterizarse como tensionadas entre el abandono y la gentrificación, según la lógica de la ciudad capitalista para la cual su centralidad actual y potencial son fuentes siempre a tener en cuenta del cual extraer valor (Dos Santos Gaspar, 2010). Algunas áreas han sufrido mucho más el deterioro característico de los cascos tradicionales latinoamericanos (Lozano Rivera, 2019), tras sucesivas crisis de los sectores medios bajos y medios que los habitaban. Expulsión de su población hacia zonas periféricas de la ciudad e incluso más allá, dieron como resultado la precarización de su stock edilicio, un conjunto significativo de viviendas de fines del siglo XIX y principios del siglo XX (Ures y Bustillo, 2014). Pero la recapitalización de estas zonas encierra el peligro de volver a despertar dinámicas de expulsión de los residentes, tanto de aquellos que resistieron la tendencia general durante décadas y no abandonaron las principales centralidades urbanas, como de quienes llegaron a residir también allí, en sucesivas oleadas migratorias, sea por la tendencia estructural del vaciamiento del medio rural uruguayo como en los últimos años por una nueva población procedentes de países latinoamericanos, en especial caribeños. La oferta de pensiones operando en estas casas precarizadas, la cercanía a los servicios públicos principales y todo lo que ofrece la centralidad para economizar los traslados y organizar la vida de los recién llegados, empuja a optar por estos territorios para residir (Fossatti y Uriarte, 2018).

El nivel de precariedad de las formas de habitar en tales contextos es significativo, desde la inestabilidad de las condiciones contractuales a la situación arquitectónica de los ambientes, así como de la calidad de lo que llamamos espacios públicos. Una de las áreas más extensas dentro de los territorios del histórico segundo ensanche es el conocido como barrio del Cordón, la expansión más directa del primer ensanche (actual Centro de la ciudad) que a su vez fue la extensión de la ciudad fundacional (la Ciudad Vieja). El Cordón se desborda sin cesar a lo largo de su historia, cargada de personalidades, acontecimientos y sede de instituciones emblemáticas de la historia social del Uruguay (Barrios Pintos, 1971). Incluso se ocupación es muy anterior al decreto urbanístico, remontándose a los primeros tiempos coloniales junto a La Aguada, el otro barrio contiguo más próximo a la península fundacional, subsumido también a la lógica impuesta por la operación urbanística decimonónica de ensanchamiento, en su afán por ordenar y control el desarrollado socio-territorial (Capel, 2002). Dentro de este extenso 
barrio, hacia el límite difuso del norte, entre calles de alto tránsito y manzanas donde podemos encontrarnos con las mayores concentraciones de fincas abandonadas o en franco deterioro, nos encontramos con una dinámica urbana clave para la comprensión de los fenómenos que aquí nos ocupan. Las negociaciones, contradicciones y conflictos que hacen a la vida cotidiana de diversos colectivos, la acción de movimientos sociales y los efectos casi imperceptibles de la rutina de otros residentes, se conjugan en una experiencia etnográfica paradigmática, la cual es el centro de este artículo.

\section{Una esquina "recuperada"}

Gracias a las travesías por la ciudad de uno de los integrantes del equipo general, se llegó a identificar este lugar particularmente significativo para los fenómenos que aquí investigamos. ${ }^{4}$ Ubicado en una esquina del norte del Cordón, sobre una de las calles que constituye una de las vías de circulación para flujos de transporte colectivo urbano y metropolitano de mayor densidad, dentro del área de influencia del llamado "eje universitario" (Eira, 2019: 70-73), se generó un espacio en principio bastante enigmático ante la mirada cotidiana. Lo que percibimos al comienzo fue una ruina edilicia, donde se habían tomado las medianeras como superficies para la elaboración de grafitis, entre los que destacaba uno donde en la parte superior se podía leer: "Plaza Acción Directa”. También había otros elementos, como muritos de ladrillo dispuestos en el perímetro del predio, y plantas, arbustos y un árbol joven en medio del área delimitada. Es así que comenzamos un proceso de aproximación etnográfica de este espacio urbano, sobre sus cualidades constitutivas, sus usos y significaciones por parte de diversos actores sociales que progresivamente fuimos identificando como decisivos al respecto. Ello nos llevó a otros lugares, tanto de la ciudad como virtuales en el ciberespacio, en la búsqueda de quienes se autoproclamaban como los agentes directos de su diseño y gestión.

\footnotetext{
${ }^{4}$ Para la elaboración de este artículo se tomó en cuenta la práctica desarrollada junto al Grupo 7 de nuestro Taller de Etnografia: Comunicación y Ciudad, FIC-Udelar, en su edición 2017, integrado por Federico Dalmaud, Dilva Devita y Denise Vigo.
} 


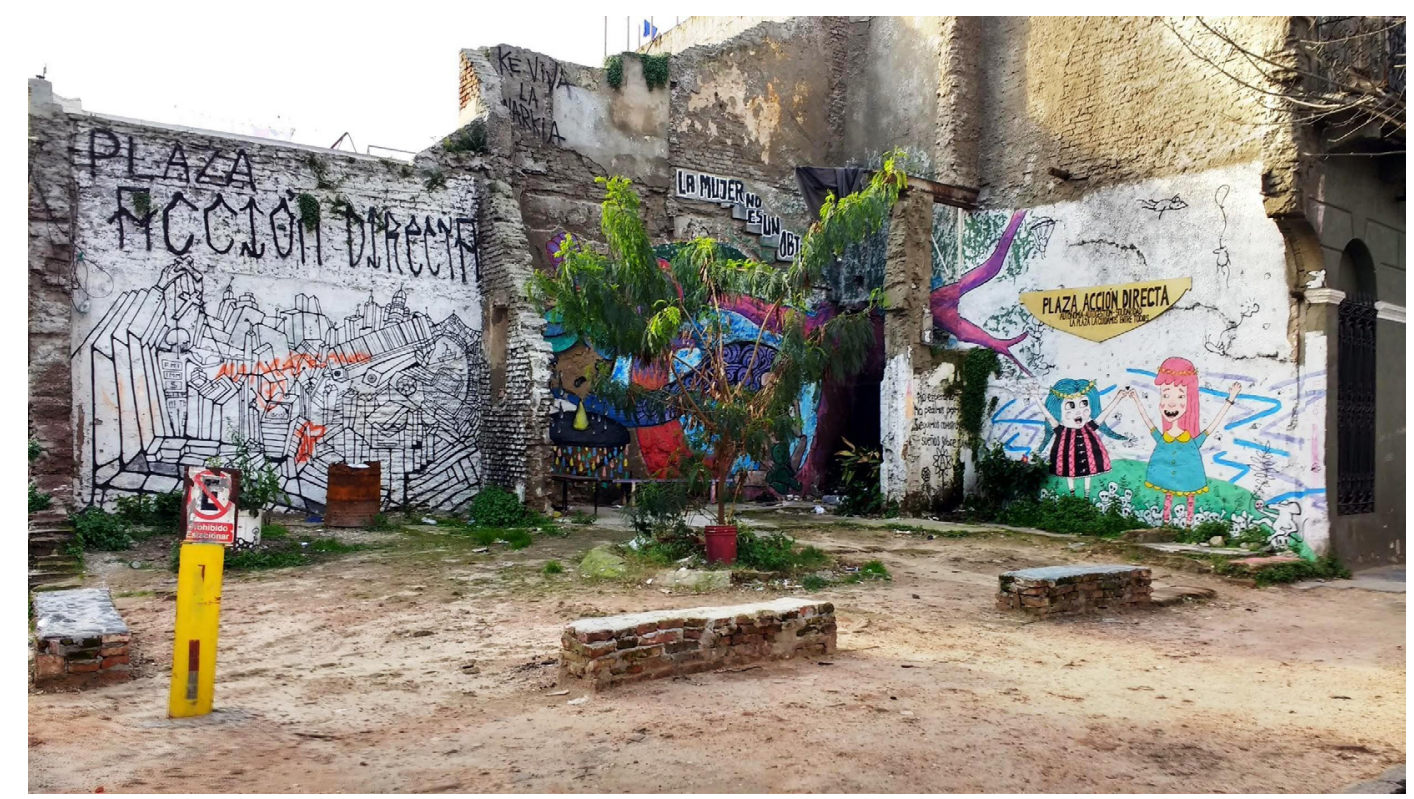

1. Plaza Acción Directa, Cordón, Montevideo. Fuente: Denise Vigo, 2017.

El trabajo de campo se inicia frecuentando el espacio en diferentes momentos de los días de la semana. En las primeras observaciones se toma registro de lo que acontece tanto dentro como a su alrededor, del tipo de subjetividades y actantes involucrados en ello, donde los objetos y las huellas de los usos ganan una especial relevancia, debido a una suerte de clandestinidad que orbita sobre un lugar cargado de incógnitas. Tenemos la sensación de que se trata de un sitio abandonado, incluso por la persistente presencia de residuos desperdigados por doquier. Los grafitis nos indican la existencia de un colectivo que se proclama anarquista y que sería el responsable de haber convertido la ruina en una oportunidad para la emergencia de un alternativa en clave del habitar urbano, según un "urbanismo desde abajo" disruptivo y emergente desde las tensiones con la lógica imperante y abierto a la experimentación (Correa, Grebert y Gómez Angelero, 2018).

Nos resulta interesante abrirnos a una percepción distinta respecto al espacio urbano a partir de sitios como este, que se definen como resultado de una acción política y artística. Lo que comunica y como lo hace es compartido y a un tiempo radicalmente distinto a aquellos ambientes diseñados, construidos y transformados por el residir cotidiano de sus habitantes. En este caso, parecería que no es necesario contar con la presencia corpórea de quienes parecen ser los responsables de su materialización, el presunto colectivo anarquista del que informan las pinturas en las paredes. Este uso pictóri- 
co, incluso "háptico" de la visualidad táctil (Deleuze y Guattari, 1997) hace a un tipo de composición territorial, más cuando las referencias a estas entidades autorales colectivas pueden rastrearse en el ciberespacio. Se trata de un lugar que se sostiene en líneas de desterritorialización muy intensas, tendiente incluso a la disolución. El estriaje está supeditado al alisamiento de forma contundente: espacio que pretende ser nómade por definición. Las cualidades o "valencias" del grafiti como agenciamiento de la comunicación urbana parecen definir la integralidad de la espacialidad en cuestión: marginalidad, anonimato, espontaneidad, escenicidad, precariedad, velocidad y fugacidad (Silva, 2007).

Todos los intentos por establecer vínculos colaborativos con los creadores de este espacio fueron frustrados. Se encontró una fuerte negativa, más allá de fructíferos diálogos a través de redes sociales o la participación en eventos artísticos junto a los demás concurrentes. El silencio fue la actitud principal. Los acercamientos fueron generados gracias a redes de contactos que permitieron llegar a los sujetos en cuestión. La comunicación principal fue a través del chat de una red social con quien se presentó a sí mismo como uno de los autores de uno de los grafitis. Después de un intenso intercambio vino una larga pausa; contrastes de ritmos y formas de estar que hay que contemplar como parte de las situaciones etnográficas en espacios virtuales (Ardèvol, Bertrán, Callén, y Pérez, 2003). Pero el último mensaje reafirmó el carácter clandestino que envuelve a los protagonistas de esta experimentación urbana: no se quiso proseguir con el vínculo, ni compartir mayor información al respecto.

Sin dudas la situación es totalmente comprensible: la ocupación de un terreno en ruinas por parte de un colectivo de jóvenes muy presumiblemente vinculados al ámbito universitario al que también pertenecemos y relacionado a redes de actividades llevadas a cabo en otras viviendas antiguas del área y orientadas por las mismas definiciones ideológicas, en un acto ostensible para todos los involucrados e incluso explícitamente visibilizado en este paisaje de alta circulación cotidiana, requiere de tácticas y estrategias muy delicadas de manejar para no quedar en situaciones de peligro. Respetando esta convicción, proseguimos por todos las vías imaginables de indagación del fenómeno socio-territorial en cuestión, respetando éticamente la posición de los directamente involucrados, los residentes próximos y los habituales usuarios de estos espacios. Respecto a los propietarios legalmente constituidos, es significativo el hecho de tratarse de una situación de vacío formal, lo que condice con la necesidad de hacerse cargo de 
este sitio una vez se derrumbara la construcción de la casa centenario que albergara, la preocupación de algunos vecinos por el uso indebido del predio para el estacionamiento de vehículos por parte de otros desesperados por esquivar el pago tarifado, y la simpatía despertada por este grupo de jóvenes que tomó la iniciativa de hacer algo con ello para otros usos socialmente relevantes. Como se ha señalado desde los antecedentes principalmente europeos al respecto, existen diversas formas de "ocupar lo ajeno": por la necesidad de vivienda debido a la pobreza, como estrategia de alojamiento alternativa al mercado, en la forma de emprendimientos económicos, de tinte conservacionista en tanto resistencia ante el embate de modelos agresivos de desarrollo y las marcadas por fines ideológico-políticos (Pruijt en Adell Argilés, 2007: 28-29). No se trata de una categorización excluyente, y nuestro caso se corresponde con los últimos dos tipos a la vez, en tanto respuesta a las condiciones imperantes altamente nocivas para la población residente y como movilización social alternativa.

Como hemos planteado al comienzo de este artículo, nuestra investigación trata sobre fenómenos del habitar urbano en territorios tensionados entre el deterioro y la gentrificación, en la búsqueda incluso de situaciones que puedan superar en algún sentido y dimensión la dicotomía típicamente capitalista de la ciudad moderna, acentuada en su versión neoliberal extractivista (Harvey, 2004). El interés por la reutilización de las casas y predios abandonados y visiblemente en franco deterioro, que son incluso peligrosos para el transeúnte por los posibles derrumbes, y que caracterizan el paisaje en el imaginario urbano del Montevideo central de las décadas anteriores, han movilizado políticas específicas en los últimos años (Ures y Bustillo, 2014). Este caso en particular resulta por ello mismo especialmente significativo. El terreno se ubica en el sector norte del Cordón (para el que incluso se utiliza en forma más o menos generalizada la voz Cordón Norte), en una esquina de un área de $60 \mathrm{~m}^{2}$. Allí existía un inmueble de dos plantas, construido según una variante tipológica en altura de la "casa a patio" (Pantaleón, Fernández, Parodi, Abdala, Martínez y Piazza, 2002), forma arquitectónica medular en nuestra investigación centrada en La Ciudad Novísima montevideana por constituir su correlato a escala edilicia. Durante los últimos años funcionaba allí una precaria carpintería. La edificación, declarada vivienda ruinosa y en peligro de derrumbe por parte de las autoridades municipales (IM, 2014), fue demolida por ello en septiembre de 2014. El predio (Padrón 14.169) fue ocupado y recuperado para estos usos que ahora analizamos en diciembre de 2015. 
Le quitamos a una ciudad que nos anula un cacho de tierra y un cacho de muerte. Hoy una esquina en ruinas se levanta para arruinarles el juego a los poderosos. Hoy construimos un pedazo de vida, un lugar para crear otro tipo de relaciones, un lugar para compartir, mirarse a los ojos, jugar y así luchar, recuperando nuestro tiempo y nuestro espacio. [...] No hemos esperado por nadie, no hemos pedido permiso a nadie, hemos recuperado el espacio para nosotros y para los demás pensando en nuestras necesidades reales, no las del Estado, no las del negocio y la planificación urbana. En un momento en el que el barrio se reestructura echando a los vecinos pobres, llenándose de cámaras y trayendo las luces de una nueva ilusión que traerá más control y muerte, nosotros creamos resistencia, es decir, vida. Porque es vida potenciar los medios para una comunicación real y es vida oponerse al progreso del mundo del dinero. Una plaza no es suficiente, eso es segruo, pero hoy no estamos haciendo una plaza sino dándonos una nueva oportunidad. Seamos peligrosamente libres... (Periódico Anarquía, 2015).

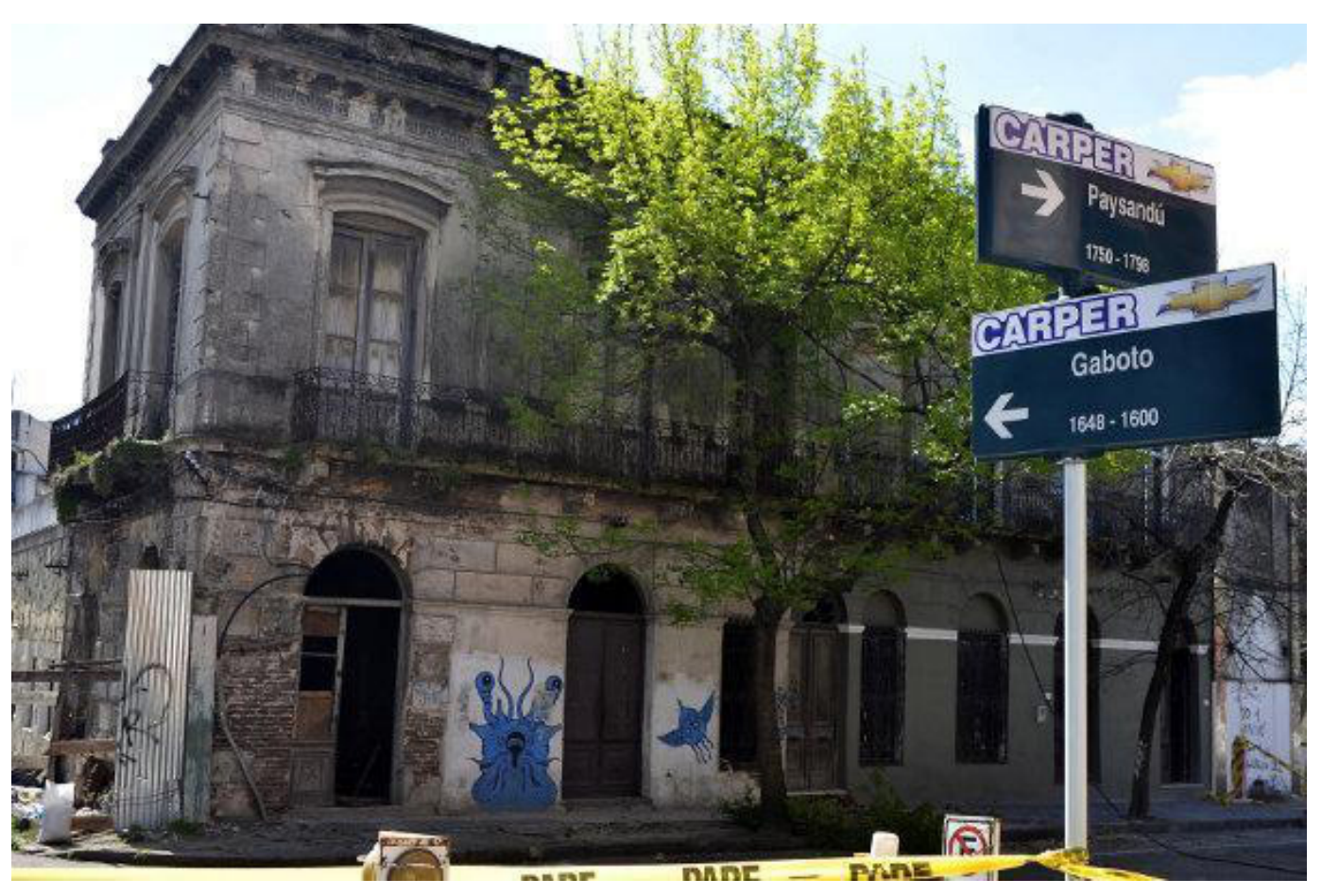

2. La antigua edificación antes de ser demolida por peligro de derrumbe, donde se ubica la actual Plaza Acción Directa, Cordón, Montevideo. Fuente: IM, 2014. 

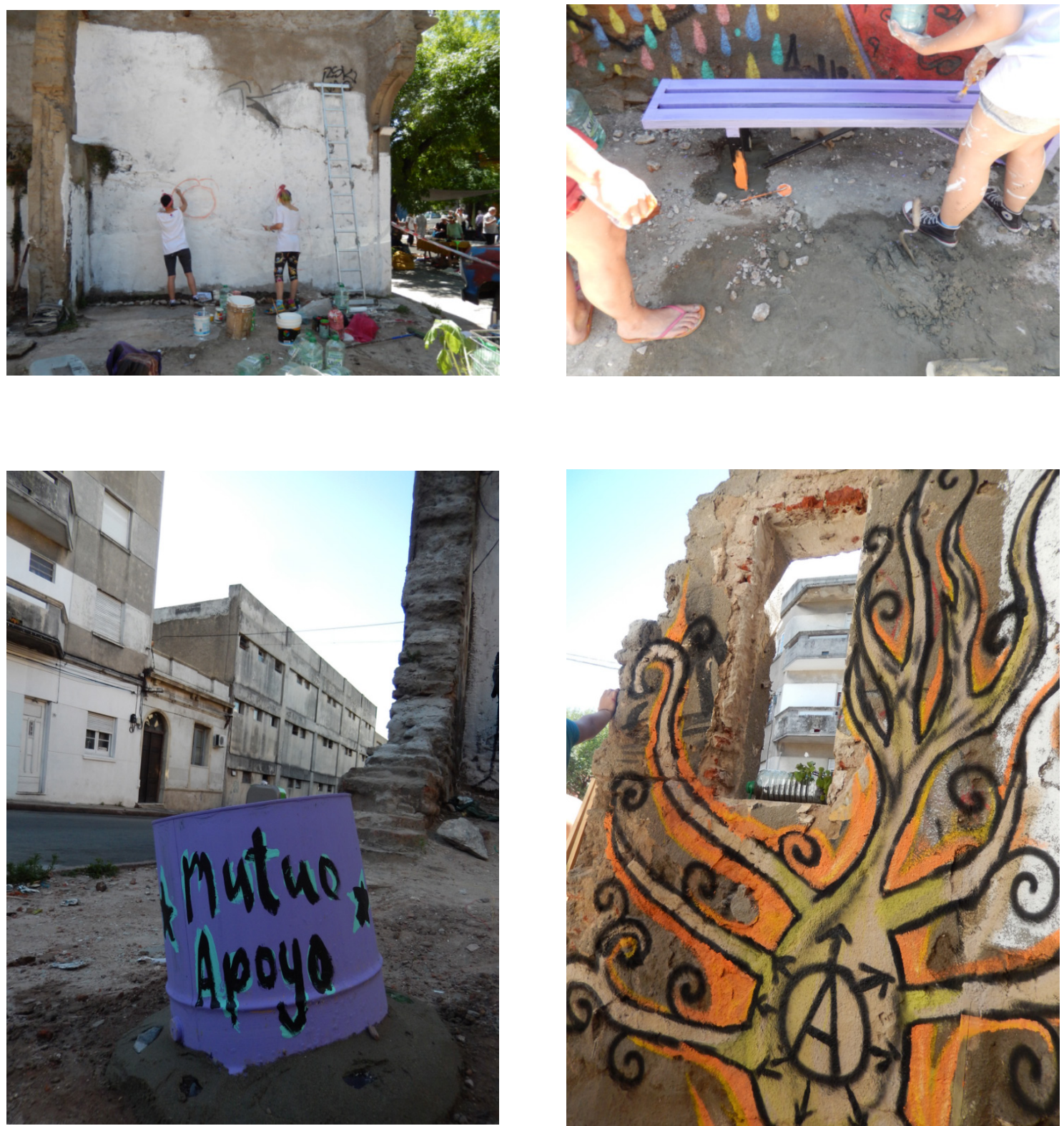

3, 4, 5 y 6. "Fotos de la recuperación de la plaza "Acción Directa" (Gaboto esquina Paysandú)". Fuente: Periódico Anarquía, 2015.

\section{Afirmar la vida contra la precariedad del habitar urbano}

En el balcón del primer piso de un edificio frente al predio sobre la calle Gaboto, fue asesinada en 2012 Soledad Barrios, una joven de 28 años, al recibir un disparo de arma de fuego al salir a ver qué sucedía calle abajo a partir de escuchar gritos, corridas y 
trifulcas desde el interior de su vivienda. Se trataba de un enfrentamiento entre barras de equipos de básquetbol que se consideran a sí mismas como fuertes rivales históricos: el equipo locatario, Cordón, con su sede a pocas calles de allí, y Welcome, con su sede también ubicada dentro de los límites oficiales del segundo ensanche montevideano, pero hacia la costa próximo al Parque Rodó. En el episodio también estuvo involucrada la policía, ya que en una primera instancia se manejó la hipótesis de que el disparo podría haber sido efectuado por un arma de su propiedad. El hecho fue mediatizado especialmente desde la prensa escrita y los informativos de televisión abierta. Fue considerado un evento más dentro de una cadena de actos delictivos protagonizados por jóvenes de estos grupos en torno a clubes deportivos. ${ }^{5}$

Las instituciones deportivas, en especial las relacionadas al básquetbol, son emblemáticas de estos territorios de la ciudad, en lo que constituyen vínculos muy estrechos entre las condiciones necesarias para la infraestructura de su ejercicio, la gestión y organización de los grupos de jóvenes y adolescentes de las familias residentes y las figuras de liderazgo surgidas de las comunidades e incluso de empresarios y políticos que encuentran en ello un ámbito privilegiado de actuación. En lo que respecta al análisis de las territorialidades, los límites de los barrios constituyen una problemática por demás interesante para su conceptualización y problematización, en el entendido de que no preexisten ni son entidades fijas y definidas en forma excluyente (Álvarez Pedrosian, 2018a). Los equipos de básquetbol constituyen expresión de estas identidades barriales y son particularmente relevantes para la comprensión de los territorios históricamente centrales de Montevideo.

Para nuestros fines es importante reconocer el aura de violencia y precariedad presente en esta suerte de semiosfera urbana, y como se perpetúa de alguna forma y se alimenta a partir de ese tipo de acontecimientos. Este episodio en particular y otros posibles que no llegaron a la órbita mediática al no tener un desenlace sangriento, deben considerarse a la hora de comprender el acercamiento a los vecinos más próximos a la

\footnotetext{
${ }^{5}$ El caso siguió siendo noticia ya que pasó a la órbita de la Justicia por una demanda civil presentada por la familia de la joven: "En una demanda civil por casi U\$S 400.000 al Ministerio del Interior, dos personas declararon ante la Justicia que la Policía fue omisa al no seguir a la hinchada de Welcome como había acordado con la Federación de Básquetbol previo al partido jugado el 14 de diciembre de 2012. Durante los incidentes entre barrabravas de Welcome y Cordón, la joven Soledad Barrios fue ultimada de un disparo [...] cuando se asomó al balcón de su apartamento, ubicado en Gaboto y Paysandú, para pedirle a los parciales revoltosos que no le rompieran el auto que había adquirido hacía poco, según surge de un expediente judicial. Por el crimen, fue privado de libertad un menor de 17 años supuestamente hincha de Cordón" (El País, 2017). Casi cinco años y medio después, el 16 de mayo de 2018, la Justicia condenó al Ministerio del Interior a pagar U\$S 100.000, aunque la demanda fue realizada al cuerpo de seguridad y a la federación deportiva (El Observador, 2018).
} 
plaza en cuestión. Asimismo, ha sido significativo el hecho de lo bien valorado que es el grupo de jóvenes autodefinidos de anarquistas que gestionan el predio, por lo menos desde los comerciantes más cercanos, quizás, con la esperanza de que estas prácticas y sus resultados sean un ejemplo de cómo existen alternativas a la estigmatización de la juventud y el dominio de la violencia y la criminalidad. Como hemos planteado, los territorios del segundo ensanche han ido configurándose como extensión máxima de una suerte de área central de la ciudad, siendo particularmente el Cordón y la Aguada los considerados como barrios más asociados a este rasgo, debido a su proximidad geográfica y su proceso histórico. Esto también puede verse en relación a la pobreza y la vida en las calles y viviendas de gran precariedad, a una violencia estructural presente en estos espacios urbanos como los actuales Ciudad Vieja y Centro (Fraiman y Rossal, 2011). Entre los vecinos entrevistados en su entorno existe una variación de los posicionamientos al respecto de las transformaciones suscitadas por esta intervención, a un tiempo que se comparte la apreciación respecto a la permanencia del peligro latente durante las noches y el casi nulo uso del espacio durante el día. La precariedad del entorno y los conflictos existentes por estas tensiones territoriales pueden leerse en diversos registros. ${ }^{6}$

A escala molecular nos encontramos con la vida en las pensiones más o menos formalizadas, concentradas especialmente en el área de transición entre lo que vimos se conoce localmente como Cordón Norte y el sur de la Aguada (como en otras aglomeraciones en el segundo ensanche y el resto de zonas más antiguas de la ciudad), operando en viviendas centenarias en condición de gran deterioro. Más próximamente, es significativo el contraste entre las instalaciones policiales y los centros de estudio y organización de colectivos de filiación anticapitalista (como la casa ocupada Centro Social Autónomo La Solidaria desalojada en 2017, la Casa de Filosofía, o más recientemente el Centro Social Cordón Norte, los dos primeros a pocas calles de allí y último hacia el área limítrofe con Tres Cruces en el entorno del Parque Plaza Líber Seregni) (La Diaria, 2017; Brecha, 2014; Casa de Filosofía, s/f; Centro Social Cordón Norte, s/f; La Solida-

\footnotetext{
${ }^{6}$ En la publicación de las autoridades municipales advirtiendo el peligro de derrumbe de la antigua casa ubicada en el predio, nos encontramos con el siguiente comentario en forma de testimonio: "Yo vivo en frente, esa casa hace años debería haber sido demolida, con el viento empezó a sacudirse como si fuera de papel. Un detalle curioso, en el edificio enfrente mataron a Soledad Barrios, con la pelea a tiros de las hinchadas de básquetbol. La piba que encontraron muerta en el balcón. Y a pocos metros estaba la Metro [Guardia Metropolitana]... los hombres de negro que no hacían nada y estaban al dope. Ahora están los azules, otros al dope... a la vuelta tenemos tremenda boca de pasta base, un mini-cante (otras casas que deberían ser demolidas, que un HDP [Hijo de Puta] transformó en pensión y les cobran 6.000 \$ la pieza a los residentes) con pendejos que juegan al fútbol y rompen” (IM, 2014).
} 
ria, s/f). A nivel molar, todo ello parece convertirse en la escenografía de un paisaje urbano marcado por el tránsito rápido interminable de vehículos particulares y sobre una de sus caras, la calle Paysandú, por el flujo constante y de gran densidad del transporte público colectivo de cobertura metropolitana durante los días laborables.

Esta situación efervescente no es nada nueva para los territorios del segundo ensanche montevideano. Como pudimos identificar a partir de otro de los ejercicios etnográficos enmarcados en esta investigación, las sedes de los principales sindicatos así como de partidos y sectores políticos de todo el espectro ideológico encuentran en él la ubicación histórica de sus sedes, más allá de algunos casos que aún se mantienen en la Ciudad Vieja, o el primer ensanche (o sea el actual Centro), y muy por debajo en otros sectores de la ciudad. Pero la relación específica con el anarquismo, los movimientos anticapitalistas y organizaciones alternativas es por demás significativa. Ello puede deberse al proceso histórico urbanístico que hemos mencionado al comienzo de este artículo, y en cómo perdura el carácter táctico y estratégico de esta zona de la ciudad, céntrica y a un tiempo amplia, conectada a todos los flujos de comunicación que la atraviesan y dotada de intersticios, espacios "entre" que permiten instalarse en viejas construcciones nobles y en la medida de las posibilidades emprender el trabajo colectivo de reforma edilicia, práctica que además va en sintonía con los propósitos perseguidos. La denominada "Plaza Acción Directa" es un caso particular de este proceso, especial en tanto se da puertas afuera, poniendo en jaque la misma idea de espacio público y permitiéndonos acceder una dimensión emergente de los fenómenos urbanos.

\section{La fuerza instituyente del anonimato en espacialidades disruptivas}

Ahora bien, lo disruptivo de esta experiencia puede encontrarse en la concepción y práctica de la acción directa de un colectivo autogestionario que encuentra en el anonimato una estrategia medular; de allí nuestra convicción de respetar dicha posición. Herederos de la tradición anarquista, y en sintonía con los movimientos de las últimas décadas especialmente focalizados en la reformulación de las formas de habitar que rigen en las grandes ciudades capitalistas del sistema-mundo (Vilaseca, 2013), caracterizadas por fuertes procesos de gentrificación y precarización de la vida de la mayoría de sus residentes, la noción de la "acción directa" para la ocupación de espacios, su 
rediseño e instalación de una lógica autogestionario alternativa es crucial: "La tríada "gesto radical-fuerza del anonimato-espacios del anonimato» sustituye a la tríada ciudadanía-espacio público-ciudad fundamento de la política llevada a cabo por el Estado de los partidos" (López Petit, 2016: XXI). En la senda del pensamiento crítico, el gesto combativo de este colectivo nos obliga a considerar, en primer lugar, la necesidad de cuestionar las lógicas hegemónicas de producción de subjetividad y mundo, y en segundo término, a hacerlo sin esperar una resolución formal definitiva, en la senda libertaria de una izquierda radical para la cual siempre existe una trampa inherente a la institucionalización de las normas, la trascendencia o mediación de códigos, como las que rigen la ciudad:

Una plaza puede ser sólo eso, un cacho de suelo y algún banco, un lugar para tomar y dejarse ver por la policía o puede ser una oportunidad única, una oportunidad de ser mejores, de ser más libres y de aprender lo que queremos y cómo hacerlo. Hemos venido a este mundo sin mucha cosa y mucha cosas nos han metido, ahora es tiempo de repensar lo que queremos. Simplemente es hora de descartar lo que no nos sirve y animarnos a hacer lo que soñemos. Sólo los llamados realistas y los miedosos hacen lo posible, por eso repiten y jamás crean nada. Crear es un acto de desobediencia, se desobedece al mundo que se deja atrás. (Periódico Anarquía, 2015).

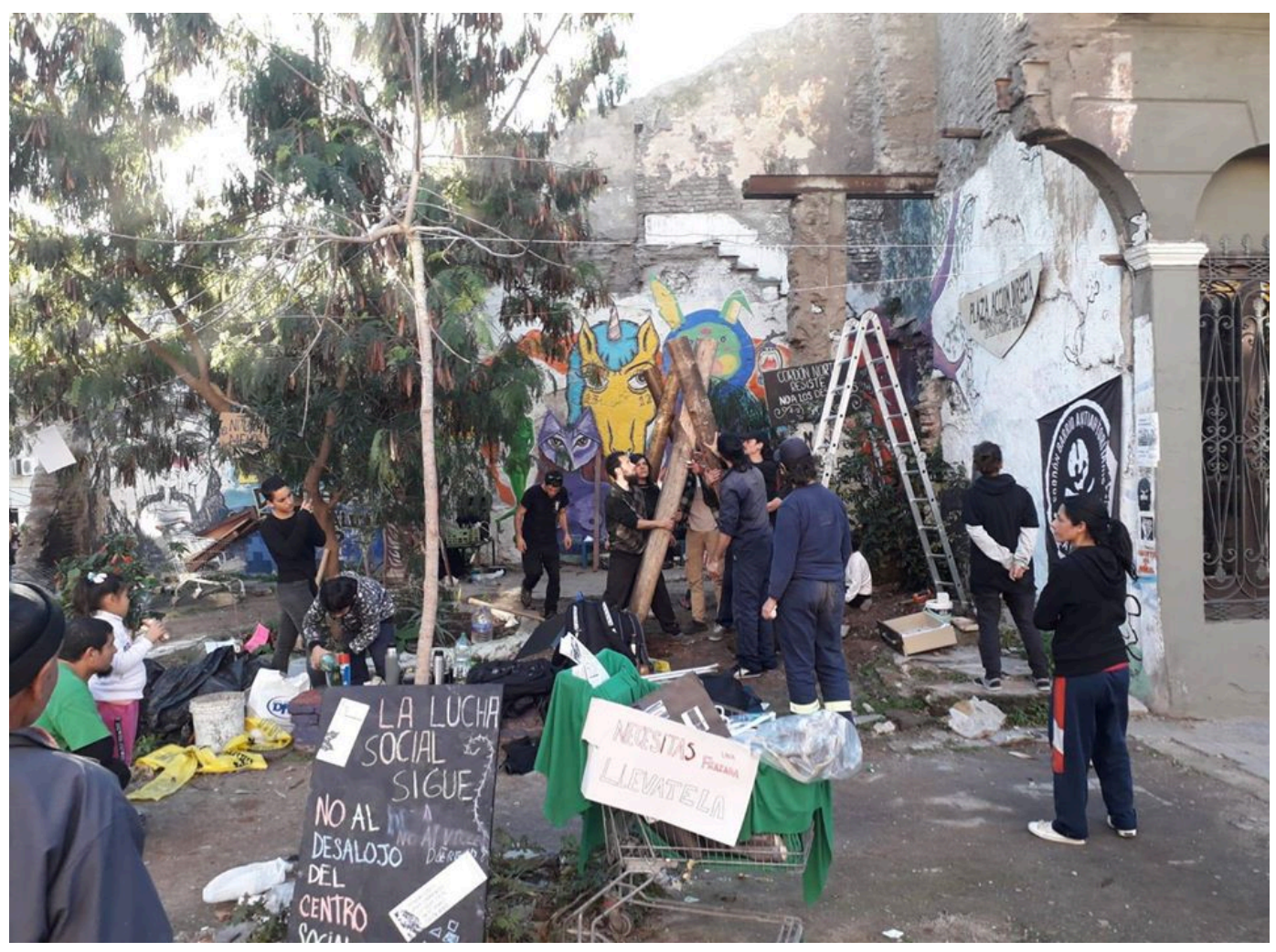


7. "Plaza "Acción Directa": Hoy, y como todos los jueves, desde las $21 \mathrm{hs}$, salimos desde el centro social (Requena y Daniel Muñoz) hacia la plazita ubicada en Gaboto y Paysandú a realizar la limpieza y mantenimiento de la misma. Arrimate....están todxs invitadxs!!! $\square$ Foto tomada en la jornada de construcción de las hamacas. Fuente: Centro Social Cordón Norte. Publicado el 16-09-19. Disponible en https://www.facebook.com/permalink.php?story_fbid=735047470295663yid=364872687313145

Por su esencia, la arquitectura está ligada tanto a la utopía como a la historia. Estas dos formadoras de la cultura humana constituyen precisamente el contexto de la arquitectura, tomado en el plano más general. En determinado sentido, el elemento de la utopía siempre es inherente a la arquitectura, puesto que el mundo creado por las manos del hombre siempre modeliza su idea del universo ideal. (Lotman, 2000: 108).

Las relaciones antagónicas del anarquismo con el Estado pueden encontrarse expresadas en las soluciones estéticas que los diversos movimientos identificados con esta ideología han generado, desde los grafitis a los blogs en el ciberespacio. Lo que sí aparece recurrentemente es la noción de un arte abierto a toda participación, no restringido a especialistas, acorde a los ideales igualitaristas y libertarios (Baigorria, 2010). El diseño resultante que va configurándose sobre la marcha y el territorio que define guarda, como hemos analizado a propósitos de otros espacios abandonados reconvertidos, un evidente carácter heterotópico (Foucault, 1999; Álvarez Pedrosian y Fagundez D'Anello, 2019). El ideal anarquista se traduce en formas adaptativas que recurren a figuras del urbanismo tradicional para la imagen de plaza, como ser la vegetación central, la disposición de bancos para sentarse, junto al muralismo de las vanguardias artísticas que durante el siglo XX fueron incorporadas y luego devinieron en diversos tipos de grafitis. Estas imágenes a su vez son capturadas fotográficamente y alimentan los sitios virtuales del colectivo que gestiona el lugar. Lo que más encontramos son alusiones a las autoridades ante las que revelarse: el sistema capitalista, patriarcal y clerical. La visibilización de la violencia hacia las mujeres y la creciente organización y accionar de los colectivos feministas se expresa en lo que denuncian los muros como se evidencia en algunos de los grafitis que encontramos. Nuestro trabajo de campo también coincidió con la desaparición del activista argentino Santiago Maldonado en la Patagonia, hecho que ameritó su alusión en los muros de la plaza y otras acciones como la marcha que se llevó a cabo en coordinación con la realizada en otras ciudades de la región por colectivos afines más allá de las fronteras nacionales. Rostros de luchadores sociales con nombre propio, de figuras icónicas, inscripciones con lemas y sentencias ideológicas, van superponiéndose en las paredes utilizadas como lienzo de un palimpsesto vivo. 


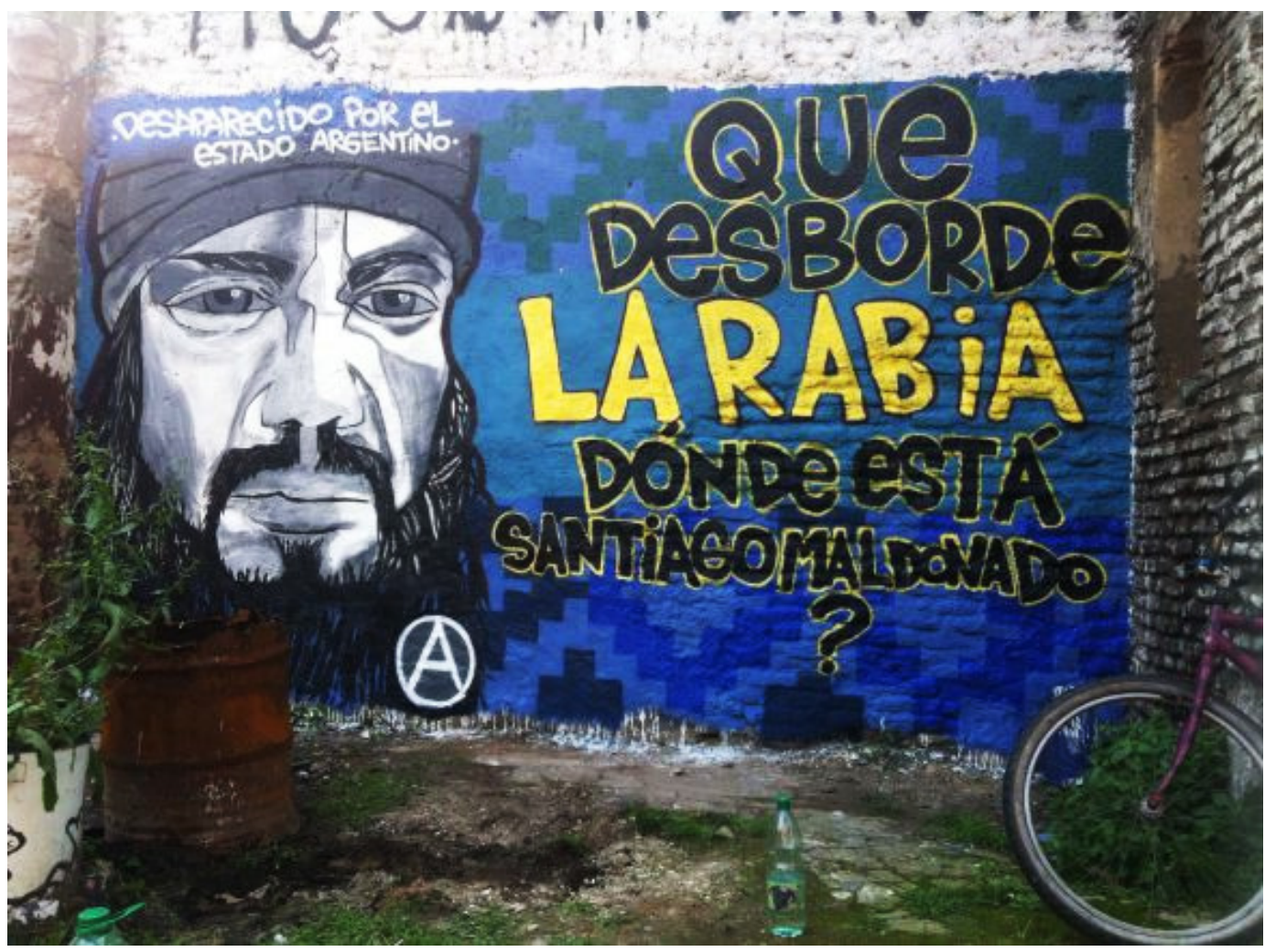

8. Mural de denuncia sobre desaparición de Santiago Maldonado. Plaza Acción Directa, Cordón, Montevideo. Fuente: Denise Vigo, 2017.

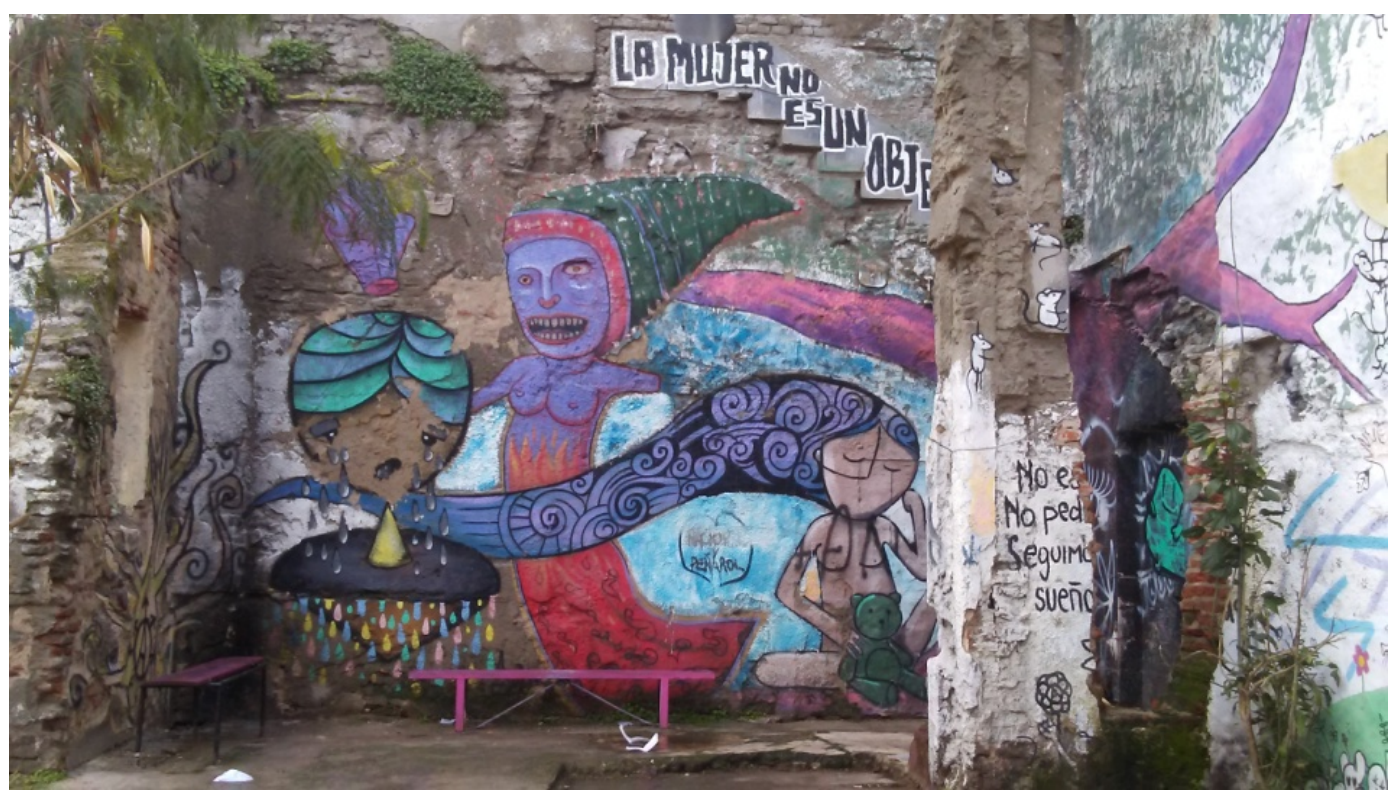

9. Mural "La mujer no es un objeto". Plaza Acción Directa, Cordón, Montevideo. Fuente: Denise Vigo, 2017. 
¿Se ha logrado transformar la realidad, generar un espacio urbano diferente? Quizás la pregunta está mal formulada, si consideramos los procesos y sus temporalidades es injusto exigir una respuesta afirmativa por el estilo. En más de un lustro, esta experiencia disruptiva en medio de la Ciudad Novísima se ha mantenido, aunque ciertamente combinando avances y retrocesos. Se puede plantear que la idea misma que rige el proyecto colectivo lo limita a una esfera reducida de posibles innovaciones: "desconoce el trabajo de aquellos supuestos "agentes externos" en la conformación de aquél ensamblaje: las relaciones contra las que reaccionan y el trabajo que hace lo vivo en ese espacio-tiempo” (Correa, Grebert y Gómez Angelero: 38-39). ¿Será, pues, que la misma práctica de autogestión así concebida implica un repliegue sobre sí del colectivo y su consecuente falta de comunicación con las otras entidades que igualmente afectan el territorio, más aún las que determinan la materialidad en cuestión? La ruptura absoluta es un ideal, y de hecho el pensar en una "plaza", denominarla de esa manera y apelar a un diseño como el resultante, nos plantea la existencia de continuidades en tradiciones antropológicas en lo relativo a la concepción de lo urbano.

Pero si bien hay una lógica de confrontación ante el estatus quo identificado con el sistema capitalista, incluido el gobierno municipal por décadas bajo una coalición de partidos de izquierdas, o una actitud de reticencia y cuidado del anonimato frente a los representantes universitarios por la misma razón de constituir agentes asociados a las instituciones hegemónicas del orden social, se identifican otros actores como instituyentes y subalternos, factibles de establecer alianzas. Vayamos a experiencias etnográficas que aportan en tal sentido, según configuraciones que se producen y reproducen en acontecimiento donde se puede evidenciar el tipo de procesos de subjetivación emergentes y las dinámicas transculturales de formas híbridas y transversales de comunicación urbana desde las lógicas expresivas en juego (Lie, 2003).

En primer lugar, la forma en que se habita este espacio los domingos durante el día, con el funcionamiento de la emblemática feria de Tristán Narvaja, que llega con una de sus derivaciones hasta allí, donde se instalan las mantas con baratijas y excentricidades para coleccionistas de objetos de poco valor comercial, ofrecidos en muchos casos por los residentes de las pensiones contiguas (Ros, 2002; CME-SUBTE, 2009). A diferencia de lo que ocurre con las fachadas de las viviendas en general, que sirven de 
telón de fondo para la disposición escenográfica del montaje de puestos, la esquina logra captar un público específico que lleva a cabo prácticas ligadas a su singularidad. En tal sentido, los paseantes dominicales encuentran en los murales y grafitis en general imágenes dignas de ser apreciadas y capturadas fotográficamente por sus teléfonos móviles. Hay ciertos puestos instalados allí, ligados al espíritu del lugar, donde se ofrecen publicaciones e indumentaria de movimientos anticapitalistas, junto a la exhibición de pancartas anarquistas. Tanto los puesteros como la mayoría de los visitantes vestían ropas negras, como de costumbre.

Luego, en forma ahora esporádica o más o menos frecuente según ritmos y velocidades que hacen a la organización de estos colectivos artísticos y políticos, la plaza es el ámbito para conciertos musicales y encuentros más amplios. Ese fue el caso del Toke Marginal III, llevado en la primavera de 2017 y al que asistimos. Fue un momento especialmente significativo para nuestra puesta en crisis de preconceptos y prejuicios provocada por las experiencias etnográficas sustentas en el extrañamiento, tensionando los imaginarios sociales en conflictivo. Esta situación se hace particularmente evidente cuando de movimientos y colectivos sociales como este se trata, dados las procesos identitarios configurados en torno a proyectos y prácticas orientadas a hacer surgir algo hasta entonces inexistente (Castoriadis, 1998).

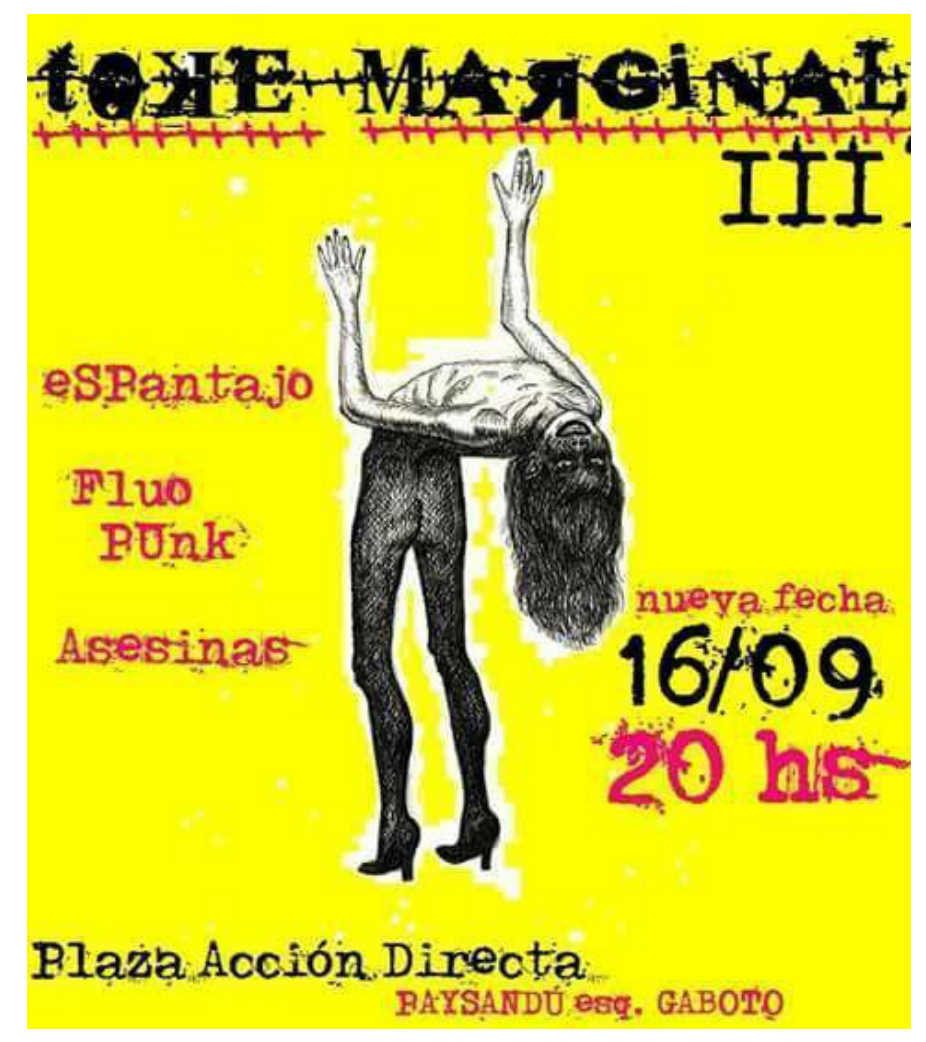


10. Afiche del Toke Marginal III. Plaza Acción Directa, Cordón, Montevideo. Fuente: https://allevents.in/montevideo/toke-marginal-iii/2007943312769800, 2017.

En el evento en cuestión se presentaron tres bandas musicales punk: Espantajo, Fluo Punk y Asesinas. Al llegar al lugar nos encontramos con una comparsa de candombe en plena esquina, antes incluso de que se detectara movimiento alguno por el espectáculo en la plaza. A partir de la hora indicada llegaron diferentes integrantes del colectivo y comenzaron a armar el equipamiento, desde el sonido a las luces, incluyendo la instalación de mesas con comida y remeras de las bandas que se presentaban para la venta. Nos presentamos, intercambiamos algunas palabras referidas a nuestra investigación, ayudamos a mover algunos de los equipos y de pronto nos encontrábamos en un espacio diferente, donde el vacío regular observado en lo cotidiano dio paso a un ámbito de encuentros intenso en su dinamismo. La esquina mostró todo su potencial en tanto punto de encuentro, de conflicto, superposición, generador de diversidad urbana, nodo de mezcla e intercambio (Solà-Morales i Rubió, 2004). Por ello debemos considerar su carácter medular en la ontología de lo urbano (Delgado, 1999; Hiernaux, 2006), especialmente potenciado en las históricas operaciones urbanísticas de los ensanches como el que nos ocupa.

Pasado el tiempo, nos encontramos con que la batea de tambores de candombe que habíamos visto calentando las lonjas y partiendo por una de las calles retornaba a la esquina. Mientras en la plaza se hacían pruebas de sonido de una de las bandas punk, el repicar de los tambores aumenta más y más, fruto de la procesión que se acercaba a donde estábamos. Por un momento pensamos que podía haber una contradicción entre ambos universos culturales y sus semiosferas, pues identificábamos a priori diferentes imaginarios sociales al respecto. Por el contrario, la reacción de los presentes fue de una compenetración por demás significativa. Todos, con sus vestimentas y maquillajes predominantemente negros dieron la vuelta hacia la calle para saludar la llegada de los tambores, dejándose afectar por la energía sonora de los territorios del candombe que lo atraviesan todo a su paso en el complejo de sensaciones y afecciones estéticas (Gonçalvez Boggio, 2007). Los cuerpos de los presentes fueron arrastrados por la polirritmia afrouruguaya; sus rostros expresaron el gozo de la posesión característica de este ritual urbano por excelencia. Observamos cómo el que realizaba la prueba de sonido para el 
concierto punk aprovechaba para realizar tomas del toque de tambores. Cuando se realizar el corte característico, estallan aplausos efusivos como de costumbre, dirigidos a los tocadores y todo el conjunto en procesión de bailarinas y acompañantes. De repente, se escucha una mezcla recién realizada con el registro elaborado, una fusión de punk y candombe.

Esto último es un buen ejemplo del tipo de procesos de subjetividad asociados a las espacialidades que nos ocupan, como decíamos más arriba, generadas en las calles en clave de rebeldía y habilitando el contacto e hibridación de tradiciones subalternas y contra-hegemónicas. En otras ciudades de América Latina y el mundo pueden darse otros fenómenos por el estilo, constitutivos de una ciudadanía instituyente en los flujos de comunicación multi-locales y a escalas variadas (Lie, 2003). Esta síntesis singular y singularizante era factible en las coordenadas existenciales del Montevideo contemporáneo, y especialmente factible y potenciado en los territorios de su Ciudad Novísima. Al transcurrir la noche fue llegando más público, incluyendo algunos vecinos de las viviendas más cercanas. También veíamos algunas ventanas cerrarse, pero sin manifestar ningún enfrentamiento directo. Nos seguíamos saludando y presentando, en una escala que habilitaba el cruce de miradas y el reconocimiento mutuo del contacto cara-acara. Una de las presentes bailaba y saltaba de forma enérgica, se lo hicimos notar a partir de un comentario y nos pusimos a dialogar. Se trataba de una extranjera que llevaba casi seis años de residente. Nos comentó que había sufrido algunos episodios de discriminación por su procedencia foránea, evidente en su expresión verbal. Pero lo que más la perturbaba era un episodio ocurrido hacía poco tiempo en un bar del Cordón donde un grupo neonazi había causado disturbios.

\section{A modo de cierre}

La “plaza Acción Directa” está por cumplir un lustro de existencia. Es un espacio de encuentro y resistencia, mantiene la precariedad contingente de la insurrección anti-sistema en su misma materialidad, especialmente en un área donde el anonimato domina con lo que de positivo y negativo ello puede tener al respecto. El colectivo que la gestiona se encarga de organizar fuerzas y conseguir insumos para su mantenimiento, en tanto fin y medio para proyectar sus propias acciones: espacio urbano alternativo y 
soporte para experimentar la cooperación y la autonomía. Las relaciones de poder con lo instituido son complejas, podemos encontrarnos con posiciones de subalternidad, antagonismo y autonomía a un mismo tiempo en diferentes dimensiones y según momentos de un proceso inacabado (Modonesi en Moreira Selva, 2016).

Todo puede suceder: que el terreno sea expropiado por las figuras legales que presumiblemente están tras toda parcela de suelo urbano, o por las autoridades municipales, o que se encuentren formas de diálogo con ellas sin subsumirse completamente a la lógica de control a la que se pretende escapar. Lugar de refugio para algunos cuida coches y otros moradores de las calles, para el armado de conciertos musicales del circuito alternativo, para la expresión gráfica del movimiento político que lo gestiona gracias a la elaboración de grafitis, la esquina parece tener una consistencia propia conquistada a fuerza de los vínculos tejidos desde una micro-política que ya pasa a ser parte del Cordón Norte y su paisaje cotidiano.

\section{REFERENCIAS}

ADELL ARGILÉS, R. “La vivienda sí preocupa: ocupantes y okupas.” Libre pensamiento, $\mathrm{n}^{\mathrm{o}}$ 54, p. 24-31, 2007.

ARDÈVOL, E. BERTRÁN, M. CALLÉN, B. Y PÉREZ, C. “Etnografía virtualizada: la observación participante y la entrevista semiestructurada en línea." Athenea Digital. Revista de pensamiento e investigación social, $\mathrm{n}^{\mathrm{o}} 3$, p. 72-92, 2003. Disponible en http://psicologiasocial.uab.es/athenea/index.php/atheneaDigital

ARÊAS PEIXOTO, F. Y GORELIK, A. "Cultura y perspectiva urbana.” En ARÊAS PEIXOTO, F. Y GORELIK, A. (comp.) Ciudades sudamericanas como arenas culturales. Buenos Aires: Siglo XXI, p. 11-19, 2016.

ÁLVAREZ PEDROSIAN, E. "Las territorialidades barriales y sus espacios de creación." En Actas del XIV Congreso de la ALAIC: Comunicación en sociedades diversas, horizontes de inclusión, equidad y democracia. GT Comunicación y Ciudad. San José: Universidad de Costa Rica, p. 72-77, 2018a. Disponible en http://alaic2018.ucr.ac.cr/sites/default/files/2019-02/GT\%2015\%20$\% 20 A L A I C \% 202018 . p d f$

ÁLVAREZ PEDROSIAN, E. "Saberes habitantes en la ciudad contemporánea: narrativas barriales de una etnografía colaborativa." Mediaciones Sociales, $\mathrm{n}^{\mathrm{0}}$ 17, p. 67-82, 2018b. Disponible en http://dx.doi.org/10.5209/MESO.60094

ÁLVAREZ PEDROSIAN, E. Y FAGUNDEZ D'ANELLO, D. "Heterotopías fabriles: bahía portuaria, flujos transnacionales y espacios industriales en reconversión." Eure. 
Revista de Estudios Urbanos y Regionales, $\mathrm{n}^{\circ} 45$ (135), p. 177-200, 2019. Disponible en http://www.eure.cl/index.php/eure/article/view/2662/1178

BAIGORRIA, O. "Estética y pensamiento anarquista. Aportes, límites y tensiones entre las vanguardias y los nuevos movimientos urbanos." Questión, no 1 (25), 2010. Disponible en http://sedici.unlp.edu.ar/handle/10915/33348

BARRIOS PINTOS, A. Montevideo. Los barrios I. Montevideo: Nuestra Tierra, 1971.

CAPEL, H. La morfología de las ciudades. Tomo I: Sociedad, cultura y paisaje urbano. Barcelona: Ediciones del Serbal, 2002.

CARMONA, L. Y GÓMEZ, MA. J. Montevideo. Proceso planificador y crecimientos. Montevideo: Farq-Udelar, 2002.

CASTORIADIS, C. Hecho y por hacer. Pensar la imaginación. Encrucijadas del laberinto $V$. Buenos Aires: Eudeba, 1998 [1997].

CORREA, G. GREBERT, L. Y GÓMEZ ANGELERO, R. "Urbanismo desde abajo. Experimentando la ciudad y sus prácticas." Inmaterial. Diseño, arte y sociedad, $\mathrm{n}^{\circ} 3$ (5), p. 21-52, 2018. Disponible en https://www.inmaterialdesign.com/index.php/INM/article/view/45

DELEUZE, G. Y GUATTARI, F. Mil mesetas. Capitalismo y esquizofrenia II. Valencia: Pre-textos, 1997 [1980].

DELGADO, M. El animal público. Hacia una antropología de los espacios urbanos. Barcelona: Anagrama, 1999.

DOS SANTOS GASPAR, S. "Gentrification: processo global, especificidades locais?" Ponto Urbe, $\mathrm{n}^{\circ} 4$ (6), 2010. Disponible en http://www.pontourbe.net/edicao6artigos/107-gentrification-processo-global-especificidades-locais

EIRA, G. Noches, relatos y huellas. Sexo/Género en los boliches del Cordón. Montevideo: CSIC-Udelar, 2019.

FOSSATTI, L. Y URIARTE, P. "Viviendo sin derecho. Migraciones latinoamericanas y acceso a la vivienda en Montevideo." La Rivada, $\mathrm{n}^{\circ} 6$ (11), p. 42-60, 2018. Disponible en http:// larivada.com.ar/index.php/numero-11/101-3-articulos/190- viviendo-sinderecho

FOUCAULT, M. "Espacios otros." Versión: Estudios de Comunicación, Política y Cultura, $\mathrm{n}^{\circ}$ 9, p. 15-26, 1999 [1967/1984]. Disponible en

http://www.lugaradudas.org/archivo/publicaciones/fotocopioteca/43_espacios_otros.pdf

FRAIMAN, R. Y ROSSAL, M. De calles, trancas y barrancas. Una etnografia sobre violencia, solidaridad y pobreza urbana. Montevideo: MI, 2011.

GONÇALVEZ BOGGIO, L. "Los territorios del candombe." En Cuerpo y subjetividades contemporáneas. Clínica bioenergética y esquizoanálisis. Montevideo: Clinicabio- 
energetica.com, 2007. Disponible en http://www.academia.edu/11497032/ Cuerpo_y_subjetividades_contemporáneas

HARVEY, D. El nuevo imperialismo. Madrid: Akal, 2004 [2003].

HIERNAUX, D. "Repensar la ciudad: la dimensión ontológica de lo urbano." Liminar: Estudios Sociales y Humanísticos, $\mathrm{n}^{\mathrm{o}} 4$ (2), p. 7-17, 2006. Disponible en: http://redalyc.uaemex.mx/redalyc/pdf/745/74540202.pdf

LIE, R. Spaces of intercultural communication. An interdisciplinary introduction to communication, culture and globalizing/localizing identities. New Jersey: Hampton Press, 2003.

LÓPEZ-PETIT, S. El discreto encanto de la politica. Barcelona: Icaria, 2016.

LOTMAN, I. "La arquitectura en el contexto de la cultura." En LOTMAN, I., La semiosfera III. Semiótica de las artes y de la cultura. Madrid: Cátedra, p. 103-112, 2000.

LOZANO RIVERA, C. "El deterioro como concepto y criterio de renovación urbana." En AGUIRRE RAMÍREZ, E. LOZANO RIVERA, C. Y MEJÍA AMÉZQUITA, V. (comp.) Deterioro, obsolescencia y configuración urbana. Reflexiones y manifestaciones. Ciudad Juárez - Mexicali: Universidad Autónoma de Ciudad Juárez - Universidad de Baja California, p. 67-83, 2019.

MOREIRA SELVA, S. Ciudad y territorios en disputa: procesos de subjetivación política en los movimientos sociales. Caso: Movimiento Popular la Dignidad (CABA, Argentina). Tesis de Maestría en Ciencias Humanas opción Estudios Latinoamericanos. Montevideo: FHCE-Udelar, 2016. Disponible en https://www.colibri.udelar.edu.uy/jspui/handle/20.500.12008/11207

PANTALEÓN, C. FERNÁNDEZ, L. PARODI, A. ABDALA, B. MARTÍNEZ, G. Y PIAZZA, N. Casa patio. Su capacidad potencial de transformación y adaptación a nuevos requerimientos funcionales. Montevideo: CSIC-Udelar, 2002.

ROS, E. "Las ferias de Montevideo: formas y razones del intercambio." En ROMERO GORSKI, S. (comp.) Anuario de Antropología Social y Cultural en Uruguay 20022003. Montevideo: FHCE, Udelar-Nordan, p. 197-203, 2002.

SILVA, A. “La ciudad como comunicación.” Diálogos de la comunicación, nº 74, 2007. Disponible en http://www.dialogosfelafacs.net/articulos-cul-23ArmandoSilva.php

SOLÀ-MORALES I RUBIÓ, M. DE. “Ciudades y esquinas urbanas.” Los monográficos de B.MM. Barcelona: Centro de Convenciones del Fórum, n 4, p. 131-134, 2004.

URES, M. Y BUSTILLO, G. "Relevamiento, conceptualización y caracterización de inmuebles visiblemente abandonados en los municipios B y C de Montevideo." En DEFENSORÍA DEL VECINO. Fincas abandonadas. Respuestas interinstitucionales para un fenómeno urbano de afectación múltiple. Montevideo: Defensoría del Vecino, p. 83$141,2014$. 
VILASECA, S. L. Barcelonan okupas. Squatter power! Madison - Teaneck: Fairleigh Dickinson University Press, 2013.

\section{Otras fuentes}

BRECHA. "La factoría.” Edición 1481. Noticia del 11-04-2014. Disponible en https://brecha.com.uy/la-factoria/

CASA DE FILOSOFÍA. Sitio de Facebook, s/f. Disponible en https://www.facebook.com/casadefilosofia/

CENTRO SOCIAL CORDÓN NORTE. Sitio de Facebook, s/f. Disponible en https://www.facebook.com/Centro-Social-Cord\%C3\%B3n-Norte-364872687313145/

CME-SUBTE Feria de Tristán Narvaja. Tiempo, señales y objetos. (Catálogo de Exposición Homenaje 100 años). Montevideo: Zona Editorial, 2009. Disponible en:

http://subte.montevideo.gub.uy/sites/subte.montevideo.gub.uy/files/articulos/descargas/f eria_de_tristan_narvaja.pdf

EL OBSERVADOR. "Justicia condenó al Ministerio del Interior a pagar U\$S 100 mil por el crimen de Soledad Barrios." Nota del 16-05-2018. Disponible en https://www.elobservador.com.uy/nota/justicia-condeno-al-ministerio-del-interior-apagar-us-100-mil-por-el-crimen-de-soledad-barrios-20185162350

EL PAÍS. "Demanda Civil. Soledad Barrios: acusan de omisión a la Policía." Nota del 19-08-2017. Disponible en https://www.elpais.com.uy/informacion/soledad-barriosacusande-omision-policia.html

INTENDENCIA DE MONTEVIDEO (IM). “Alerta.” IM Alerta por peligro de derrumbe. Nota del 12-02-2014.

https://www.montevideo.com.uy/Noticias/IM-alerta-por-peligro-de-derrumbe-uc226417

LA DIARIA. "Se realizó el desalojo de La Solidaria.” Nota del 22-3-2017. Disponible en https://ladiaria.com.uy/articulo/2017/3/se-realizo-el-desalojo-de-la-solidaria/

LA SOLIDARIA. Sitio de Facebook, s/f. Disponible en

https://www.facebook.com/Espaciolasolidaria/

PERIÓDICO ANARQUÍA. "Fotos de la recuperación de la plaza "Acción Directa" (Gaboto esquina Paysandú)." Publicado el 21-12-2015. Disponible en https://periodicoanarquia.wordpress.com/2015/12/21/plaza-accion-directa-gabotoesquina-paysandu/

Recebido: $20 / 05 / 2020$

Aprovado: 04/09/2020 